\title{
Condições de trabalho e distúrbios osteomusculares em professores da rede municipal de São Paulo
}

\author{
Working conditions and musculoskeletal disorders in teachers of the São Paulo municipal network \\ Condiciones de trabajo y trastornos osteomusculares en profesores de la red municipal São Paulo
}

Recebido: 27/11/2021 | Revisado: 04/12/2021 | Aceito: 12/12/2021 | Publicado: 20/12/2021

\author{
Alessandra Rodrigues de Souza \\ ORCID: https://orcid.org/0000-0002-5693-7252 \\ Pontifícia Universidade Católica de São Paulo, Brasil \\ E-mail: alessandrafisio92@gmail.com \\ Juliana Schulze Burti \\ ORCID: https://orcid.org/0000-0002-9737-7394 \\ Pontifícia Universidade Católica de São Paulo, Brasil \\ E-mail: juschulze@gmail.com \\ Rafaela Valiego de Souza \\ ORCID: https://orcid.org/0000-0001-7795-0096 \\ Universidade de São Paulo, Brasil \\ E-mail: rafafeital@hotmail.com \\ Susana Pimentel Pinto Giannini \\ ORCID: https://orcid.org/0000-0002-1855-0655 \\ E-mail:ppgiannini@gmail.com \\ Thelma Mello Thomé de Souza Ferreira \\ ORCID: https://orcid.org/0000-0002-2393-3888 \\ Pontifícia Universidade Católica de São Paulo, Brasil \\ E-mail: thelmamtsp@gmail.com \\ Bianca Martins Castro \\ ORCID: https://orcid.org/0000-0002-0315-8255 \\ Pontifícia Universidade Católica de São Paulo, Brasil \\ E-mail: bibivipy@gmail.com \\ Leslie Piccolotto Ferreira \\ ORCID: https://orcid.org/0000-0002-3230-7248 \\ Pontifícia Universidade Católica de São Paulo, Brasil \\ E-mail:lesliepferreira@gmail.com
}

\begin{abstract}
Resumo
Introdução: desde a antiguidade a atividade profissional esteve relacionada com transtornos de saúde associados às condições impróprias de trabalho, advindas principalmente de posturas inadequadas e atividades repetitivas de diversos segmentos corporais. Uma das classes mais afetadas é o professor, e novas propostas de promoção de saúde são necessárias, diante de novas demandas da sociedade contemporânea. Objetivo: analisar as queixas relacionadas à saúde, referidas por professores da rede municipal de São Paulo, durante participação em curso oferecido na modalidade híbrida, de ensino à distância (EAD), com encontros presenciais. Metodologia: pesquisa de caráter analítico e observacional. Participaram 257 professores que completaram 40 aulas/horas do curso híbrido, divididas em três encontros presenciais e oito módulos obrigatórios. Foram examinados os dados dos fóruns de discussão online do curso, analisando-se as principais queixas relacionadas à ambiente, organização de trabalho e distúrbios corporais relatados pelos docentes. Resultados: dentre as 565 queixas registrada, referentes a distúrbios musculoesqueléticos foram as mais citadas (398-70,4\%) seguidas pelas vocais (64-11,3\%), distúrbios anatômico-funcionais (54-9,5\%) e queixas alérgicas (49-8,6\%). Foram relatadas ainda 470 queixas referentes ao ambiente e 184 sobre organização de trabalho. Conclusão: Os professores apontaram queixas referentes ao ambiente físico, à organização de trabalho e aos distúrbios musculoesqueléticos, mostrando um ambiente de trabalho com fatores negativos, que podem refletir diretamente sobre a saúde.
\end{abstract}

Palavras-chave: Professores; Postura; Ergonomia; Distúrbios; Saúde do trabalhador.

\begin{abstract}
Introduction: since ancient times, professional activity has been related to health disorders associated with working conditions, arising mainly from inadequate postures and repetitive activities of different body segments. One of the most affected classes is the teacher, and new health promotion proposals are required, given the new demands of contemporary society. Objective: to analyze health-related complaints regarding teachers from the municipal network of São Paulo, during their participation in a course offered in hybrid modality, including distance learning (DL) and face-to-face meetings. Methodology: analytical and observational research. 257 teachers participated who completed 40 classes/hours
\end{abstract}


of the hybrid course, divided into three face-to-face meetings and eight mandatory sets. Data from the course's online discussion forums were examined, analyzing the main complaints related to the environment, work organization and bodily disturbances reported in the documents. Results: among the 565 registered complaints, those referring to musculoskeletal disorders were the most cited (398-70.4\%), followed by vocal (64-11.3\%), anatomical-affected disorders (54-9.5\%) and allergic complaints (49-8.6\%). There were also 470 complaints related to the environment and 184 about the organization of work. Conclusion: Teachers pointed out complaints regarding the physical environment, work organization and musculoskeletal disorders, showing a work environment with negative factors, which can directly reflect on health.

Keywords: Teachers; Posture; Ergonomics; Disorders; Worker's health.

\section{Resumen}

Introducción: desde la antigüedad, la actividad profesional se ha relacionado con problemas de salud asociados a las condiciones de trabajo, principalmente derivados de una postura inadecuada y actividades repetitivas de diferentes segmentos corporales. Una de las clases más afectadas es la docente, y se necesitan nuevas propuestas de promoción de la salud, dadas las nuevas demandas de la sociedad contemporánea. Objetivo: analizar las quejas relacionadas con la salud de los docentes de la red municipal de São Paulo, durante su participación en un curso ofrecido en la modalidad híbrida, educación a distancia (EAD), con reuniones presenciales. Metodología: investigación analítica y observacional. Participaron 257 docentes que completaron 40 clases / horas del curso híbrido, dividido en tres encuentros presenciales y ocho series obligatorias. Se analizaron los datos de los foros de discusión online del curso, analizando las principales quejas relacionadas con el medio ambiente, la organización del trabajo y las alteraciones corporales reportadas en los documentos. Resultados: de las 565 quejas registradas, las referidas a trastornos musculoesqueléticos fueron las más citadas (398-70,4\%), seguidas de las vocales (64-11,3\%), anatómicas (54-9,5\%) y alérgicas (49-8,6\%).). También hubo 470 quejas relacionadas con el medio ambiente y 184 sobre la organización del trabajo. Conclusión: Los docentes señalaron quejas sobre el entorno físico, la organización del trabajo y los trastornos musculoesqueléticos, evidenciando un entorno laboral con factores negativos, que pueden repercutir directamente en la salud.

Palabras clave: Profesores; Postura; Ergonomía; Trastornos; Salud del trabajador.

\section{Introdução}

Segundo Delcor et al. (2004), o trabalho humano é considerado "fonte de realização, satisfação e prazer", fazendo parte das necessidades para a sobrevivência, com papel importante na construção de identidade das pessoas. Por outro lado, pode também ser fonte nociva, levando a incômodos e distúrbios (Martins, 2012). Desde a antiguidade, a atividade profissional está relacionada a transtornos ocasionados por condições impróprias de trabalho e de ambiente, posturas inadequadas e atividades que exigem movimentos repetidos de determinados segmentos corporais (Coelho et al., 2010).

Algumas categorias profissionais são mais afetadas por distúrbios ocupacionais, e dentre essas está o professor, cujo trabalho envolve tarefas que se inter-relacionam e que envolvem múltiplos fatores e tarefas (Mango et al., 2012). As tarefas do professor também podem receber interferências do ambiente, do relacionamento com os alunos e equipe pedagógica, fatores que podem influenciar sua saúde (Latino, 2009 e Souza et al., 2017).

Dentre as doenças ocupacionais mais relevantes, estão as Doenças Osteomusculares Relacionadas ao Trabalho (DORT), que chegam a 11,19\% dos benefícios concedidos por afastamentos do trabalho pelo Instituto Nacional de Seguridade Social (Ministério do Trabalho, 2018). As Lesões por Esforços Repetitivos (LER) e os Distúrbios Osteomusculares Relacionados ao Trabalho (DORT) são definidos como danos no sistema musculoesquelético que ocorrem por utilização excessiva e falta de tempo adequado para recuperação. Os fatores de risco para DORT são multifatoriais e estão relacionados com carga, repouso, frequência e intensidade do trabalho, envolvendo assim aspectos biomecânicos, cognitivos, sensoriais, afetivos e organizacionais (Ministério da Saúde, 2012).

O ambiente e a organização do trabalho são fatores associados à saúde do trabalhador, e quando se trata de professores, ruídos internos e externos a sala de aula, presença de poeira, adoção de posturas inadequadas, excesso de alunos por turma, infraestrutura ruim, falta de organização em relação aos materiais e à sala de aula ou problemas de relacionamento em equipe são fatores de ambiente e organização que podem prejudicar o rendimento e a qualidade de vida desses profissionais (Batista et al., 2010 e Houtte et al., 2012). 
Há na literatura pesquisas que mostram os distúrbios que mais acometem os professores são os distúrbios de voz, musculoesqueléticos e psíquicos, como a depressão, por exemplo (Cantor et al., 2013 e Ng et al., 2019). Estudo brasileiro realizado com professores revelou prevalência de dor musculoesquelética em 73,5\% da população estudada, e os cinco problemas de saúde mais frequentemente relatados foram: vocais $(49,9 \%)$, alérgicos $(47,5 \%)$, transtornos mentais $(37,1 \%)$, problemas circulatórios $(36,0 \%)$ e digestivos (32,0\%) (Ceballos et al., 2015).

Considerando esses dados e visando o bem-estar e prevenção de distúrbios ocupacionais em professores, o LaborVox da Pontifícia Universidade Católica de São Paulo, junto com a prefeitura municipal de São Paulo, realizou um trabalho de educação em saúde. A proposta era voltada para sensibilizar o professor quanto aos cuidados vocais, minimizando os agravos à saúde, reconhecendo que a voz é um dos principais recursos e instrumento de trabalho do docente, além de importante forma de expressão, criação de vínculos, comunicação intersubjetiva e importante elo de relação professor-aluno no processo ensinoaprendizagem (Giannini et al., 2012).

Inicialmente, o trabalho foi projetado para ser oferecido por meio de oficinas presenciais, porém, diante da boa receptividade e à necessidade de atender um maior número de professores, viabilizou-se a possibilidade de transformar a oficina em curso denominado Promovendo o bem-estar do professor, utilizando a modalidade hibrida, combinando encontros presenciais e módulos oferecidos de forma remota (Ferreira et al., 2015 e Ferreira et al., 2019). Para a Organização Mundial de Saúde (OMS) o uso de tecnologias da informação e comunicação é uma oferta de serviço nos casos em que a distância é um fator crítico para o cuidado em saúde (OMS, 2006).

Dessa forma, o curso foi planejado e viabilizado por meio da plataforma Moodle (Ferreira et al., 2015) e no decorrer das primeiras turmas, outras demandas foram surgindo, criando a necessidade da integração de outros profissionais da saúde na equipe. Um dos profissionais inseridos na equipe foi o fisioterapeuta, que agregou ao curso conhecimentos relacionados aos cuidados com o corpo, hábitos posturais e ergonomia. Essa inclusão foi importante pois sabe-se que a prevalência das DORT é alta entre os trabalhadores e essas possuem grande potencial de gerar desconfortos e incapacidade. Medidas de promoção da saúde e prevenção das DORT tornam-se úteis no ambiente de trabalho. Um exemplo desse tipo de abordagem foi apresentado por uma pesquisa feita em 2020, que verificou o efeito de um método terapêutico-pedagógico de conscientização e reeducação postural realizado por meio da transmissão de informações teórico-educativas e prática de exercícios terapêuticos, chamado Escola de Posturas, como alternativa terapêutica e preventiva dentro do espaço laboral. Os pesquisadores verificaram melhora da flexibilidade, dor e qualidade de vida nos trabalhadores submetidos à intervenção (Camilo et al., 2020).

Diante da alta prevalência de distúrbios ocupacionais entre os professores e da necessidade de um melhor conhecimento sobre esses para que medidas de promoção de saúde adequadas sejam elaboradas, o objetivo deste trabalho foi analisar as queix as relacionadas à saúde, ambiente e organização do trabalho, referidas por professores da rede municipal de São Paulo, durante a participação em um curso oferecido na modalidade à distância.

\section{Metodologia}

Este estudo de caráter analítico e observacional foi cadastrado na Plataforma Brasil e aprovado pela Comissão de Ética da Pontifícia Universidade Católica de São Paulo sob o n ${ }^{\circ}$ CAAE 52496715.9.0000.5482. Todos os participantes assinaram Termo de Consentimento Livre e Esclarecido.

\subsection{Seleção de amostra}

A amostra foi composta por professores da rede municipal da cidade São Paulo que faziam parte da $4^{a}$ Turma do curso 
em questão, conforme mencionado anteriormente, oferecido pela cidade São Paulo em parceria com a Pontifícia Universidade Católica de São Paulo ( PUC-SP). Os professores foram convidados por meio de Diário Oficial, sendo ofertadas 300 vagas. Os docentes foram divididos em oito turmas, cada uma delas regida por um tutor. $\mathrm{O}$ curso foi validado para fins de promoção e evolução na carreira dos professores, fato que facilitou a adesão.

\subsection{Coleta de dados}

O curso foi composto por um total de 40 horas distribuídas de forma híbrida, com três encontros presenciais ( 8 horas) e oito módulos oferecidos na modalidade de Educação à distância (EAD) (32 horas), por meio da plataforma Moodle. Os três encontros presenciais foram realizados no início, no meio e ao encerramento do curso.

Cada um dos oito módulos continha a apresentação do conteúdo, elaborado por especialistas da Fonoaudiologia e da Fisioterapia, estabelecido em forma de slides; perguntas para estimular a discussão em forma de fórum; e um questionário para avaliar os participantes quanto ao conteúdo apresentado. Nesses foram tratados os seguintes conteúdos: O que é voz; Cuidados com a voz; Voz no trabalho docente; Corpo, Postura e voz; Respiração; Articulação, Fala e Ressonância; Expressividade; e Voz e emoção (Piccolotto et al., 2019).

Ao final de cada módulo, o participante era incentivado pelo tutor, responsável de cada turma, compostas em média por 32 professores. a participar de um fórum de discussão, quando respondia as questões apresentadas para sensibilizá-lo quanto à temática de cada módulo (Piccolotto et al., 2019).

O Quadro 1 exemplifica o conteúdo e perguntas dos módulos 3 e 4, respectivamente Voz no trabalho docente e Corpo, postura e voz, temáticas que serão analisadas neste artigo.

Quadro 1. Conteúdo abordado e perguntas realizadas nos fóruns dos módulos 3 e 4 do curso "Promovendo o Bem-Estar vocal do professor.

\begin{tabular}{|c|c|c|}
\hline MÓDULO & CONTEÚDO & PERGUNTAS (dos fóruns) \\
\hline $\begin{array}{c}\text { Módulo 3 } \\
\text { "Voz no trabalho } \\
\text { docente" }\end{array}$ & $\begin{array}{c}\text { - Condições adversas do trabalho do docente, } \\
\text { quanto ao ambiente físico e a organização do } \\
\text { trabalho. } \\
\text { - Informações e discussões sobre as condições de } \\
\text { trabalho e como estas podem interferir no bem- } \\
\text { estar vocal, exemplos: ruídos, poeira e pó de giz, } \\
\text { ventiladores ou ar-condicionado; excesso de } \\
\text { alunos por classe, excesso de trabalho, violência } \\
\text { e indisciplina. }\end{array}$ & $\begin{array}{c}\text { Você se percebeu em alguma das situações } \\
\text { citadas nesse módulo? O que você acha que } \\
\text { pode ser feito para tentar mudar as situações } \\
\text { do ambiente físico e da organização do } \\
\text { trabalho que podem estar prejudicando a } \\
\text { saúde dos trabalhadores de sua escola? Na } \\
\text { sua escola tem CIPA? Se sim, ela é atuante? } \\
\text { O que tem feito? Se não, você acha } \\
\text { interessante a ideia da CIPA? Por quê? }\end{array}$ \\
\hline $\begin{array}{c}\text { Módulo } 4 \\
\text { "Corpo, postura e } \\
\text { voz" }\end{array}$ & $\begin{array}{l}\text { - Importância da postura adequada e da } \\
\text { consciência corporal durante a jornada de } \\
\text { trabalho; } \\
\text { - Prevenção de lesões musculoesqueléticas e } \\
\text { influência da postura na voz. } \\
\text { - Sugestões com ilustrações explicativas de } \\
\text { exercícios para serem feitos antes, durante e após } \\
\text { o expediente, bem como figuras reforçando } \\
\text { posturas e atitudes que devem ser evitadas. }\end{array}$ & $\begin{array}{l}\text { Você percebe alguma parte mais tensa no seu } \\
\text { corpo durante sua atividade profissional? O } \\
\text { que você tem feito para melhorar? Dos } \\
\text { exercícios apresentados nesse módulo, qual } \\
\text { ou quais você colocou em prática? O que } \\
\text { percebeu? }\end{array}$ \\
\hline
\end{tabular}

Fonte: Autores (2021).

\subsection{Análise de dados}

Os dados foram gerados a partir dos apontamentos dos professores, ao responderem as perguntas abertas disparadoras nos fóruns de discussão. Para cumprir preceitos éticos, os nomes dos participantes foram removidos. Em particular para este artigo, foram categorizados aqueles apontamentos que se constituíam de queixas em relação à saúde, ambiente e organização do 
trabalho.

Na primeira etapa, cada relato discorrido pelos participantes, foi copiado individualmente do site do curso e registrado em forma de texto no Microsoft Word. Posteriormente foram categorizadas em planilha do Microsoft Excel de acordo com os temas: queixas relacionadas à saúde, ao ambiente e à organização do trabalho, relatadas em qualquer um dos oito módulos.

Para efeito da análise estatística, os itens foram reorganizados da seguinte forma: 1. Queixas referentes: a) ao ambiente, por exemplo, ruídos, poeira e infraestrutura; b) a organização de trabalho, como excesso de trabalho, indisciplina e violência; e 2. Queixas relacionadas a saúde: a) Distúrbios de voz: rouquidão, perda de voz, cansaço ao falar entre outros; b) Distúrbios anatômico-funcionais: tendinites, bursites, hérnias de disco entre outros; c) Distúrbios alérgicos: menção a rinite, sinusite e espirros constantes; e d) Distúrbios musculoesqueléticos: referência a dor, tensão e cansaço muscular.

Foi realizada a análise descritiva dos dados por meio de frequências absolutas (n) e relativas (razão e porcentagem). Para a comparação entre os módulos, utilizou-se o teste de comparação de proporções com seus respectivos intervalos de confiança de 95\% (IC95\%). Os dados foram digitados e analisados no programa Excel para Windows versão 10.

\section{Resultados}

A amostra foi composta por 257 professores que completaram os oito módulos do curso híbrido e que ao participarem registraram 1219 apontamentos, sendo 654 (53,5\%) queixas referentes ao contexto de trabalho e 565 (46,3\%) referentes a saúde.

Dentre as queixas relacionadas ao contexto de trabalho $71,9 \%$ são relacionadas ao ambiente e $28,1 \%$ à organização, representando mais de 2,5 queixas sobre a temática por participante. Ao analisar essas queixas em relação aos módulos observase que o módulo "Voz no trabalho docente" foi o que proporcionou maior número de apontamentos, com 77,66\% das 470 queixas de ambiente e $61,41 \%$ em relação as 184 queixas de organização do trabalho (Tabela 1).

Tabela 1. Número (n) e percentual (\%) de queixas em relação ao ambiente e organização do trabalho, de acordo com os módulos do curso $(\mathrm{n}=654)$.

\begin{tabular}{|c|c|c|c|c|}
\hline \multirow{3}{*}{ Módulos } & \multicolumn{4}{|c|}{ Queixas } \\
\hline & \multicolumn{2}{|c|}{ Ambiente } & \multicolumn{2}{|c|}{ Organização do trabalho } \\
\hline & $\mathrm{n}$ & $(\%)$ & $\mathrm{n}$ & $(\%)$ \\
\hline O que é voz? & 14 & $(2.98)$ & 4 & $(2.17)$ \\
\hline Cuidados com a voz & 60 & (12.77) & 0 & $(0.00)$ \\
\hline $\begin{array}{l}\text { Voz no trabalho } \\
\text { docente }\end{array}$ & 365 & $(77.66)$ & 113 & $(61.41)$ \\
\hline Corpo, postura e voz & 0 & $(0.00)$ & 0 & $(0.00)$ \\
\hline Respiração & 0 & $(0.00)$ & 6 & $(3.26)$ \\
\hline Articulação e & 0 & $(0.00)$ & 0 & $(0.00)$ \\
\hline Ressonância & & & & \\
\hline Expressividade & 0 & $(0.00)$ & 0 & $(0.00)$ \\
\hline Voz e emoção & 31 & $(6.60)$ & 61 & $(33.15)$ \\
\hline Total & 470 & $(100.00)$ & 184 & $(100.00)$ \\
\hline
\end{tabular}

Fonte: Autores (2021).

Quanto às queixas relacionadas à saúde (tabela 2) a maioria (99,75\%) ocorreu no módulo "Corpo, postura e voz", registrando 2,1 menções por participante. Os distúrbios musculoesqueléticos foram responsáveis pelo maior registro de apontamentos (398-70,4\%) e incluíram queixas de dores, tensão e cansaço em diferentes segmentos corporais.

Tabela 2. Número (n) e percentual (\%) de distúrbios corporais, de acordo com os módulos do curso (n=565). 


\begin{tabular}{lcccccccc}
\hline \multirow{2}{*}{ Módulos } & \multicolumn{9}{c}{ Queixas } \\
\cline { 2 - 10 } & \multicolumn{2}{c}{ Vocal } & \multicolumn{2}{c}{$\begin{array}{c}\text { Anatômico- } \\
\text { funcionais }\end{array}$} & \multicolumn{2}{c}{ Alérgicos } & \multicolumn{2}{c}{ Musculoesqueléticos } \\
\cline { 2 - 10 } & $\mathrm{n}$ & $(\%)$ & $\mathrm{n}$ & $(\%)$ & $\mathrm{n}$ & $(\%)$ & $\mathrm{N}$ & $(\%)$ \\
\hline O que é voz? & 39 & $(60.94)$ & 14 & $(25.93)$ & 5 & $(10.20)$ & 1 & $(0.25)$ \\
Cuidados com a voz & 3 & $(4.69)$ & 17 & $(31.48)$ & 14 & $(28.57)$ & 0 & $(0.00)$ \\
Voz no trabalho docente & 15 & $(23.44)$ & 0 & $(0.00)$ & 15 & $(30.61)$ & 0 & $(0.0)$ \\
Corpo, postura e voz & 3 & $(4.69)$ & 7 & $(12.96)$ & 0 & $(0.00)$ & 397 & $(99.75)$ \\
Respiração & 2 & $(3.13)$ & 4 & $(7.41)$ & 10 & $(20.41)$ & 0 & $(0.00)$ \\
Articulação e & 1 & $(1.56)$ & 12 & $(22.22)$ & 5 & $(10.20)$ & 0 & $(0.00)$ \\
Ressonância & & & & & & & & 0 \\
Expressividade & 0 & $(0.00)$ & 0 & $(0.00)$ & 0 & $(0.00)$ & 0 & $(0.00)$ \\
Voz e emoção & 1 & $(1.56)$ & 0 & $(0.00)$ & 0 & $(0.00)$ & 0 & $(0.00)$ \\
\hline Total & 64 & $(100,00)$ & 54 & $(100,00)$ & 49 & $(100,00)$ & 398 & $(100,00)$ \\
\hline
\end{tabular}

Fonte: Autores (2021).

As queixas referentes à voz (64-11,3\%) foram explicitadas em sua maioria como rouquidão, falha na voz, dor de garganta, tosse, garganta seca e/ou irritada, pigarro e perda da voz ao final do dia. Os distúrbios anatômico-funcionais (54-9,5\%) foram expressos em sua maioria como tendinites, bursites, hérnias de disco, condromalácia, osteofitose e fibromialgia. Por fim as queixas alérgicas $(49-8,6 \%)$ foram mencionadas como rinite e sinusite (gráfico 1).

O Gráfico 1 ilustra a relação entre as queixas musculoesqueléticas (dor, tensão e desconforto) e as diversas partes do corpo. Fica evidente que a dor se faz presente em todas as partes do corpo analisadas, em especial coluna lombar, ombro e pernas; que a tensão se localiza mais na região do tronco, em especial nos ombros e pescoço; e o desconforto nas pernas.

Gráfico 1. Regiões dor corno e auantidade de anontamentos de dor. tensão. dor e tensão iuntos ou desconforto, durante ou ao final do dia letivo.

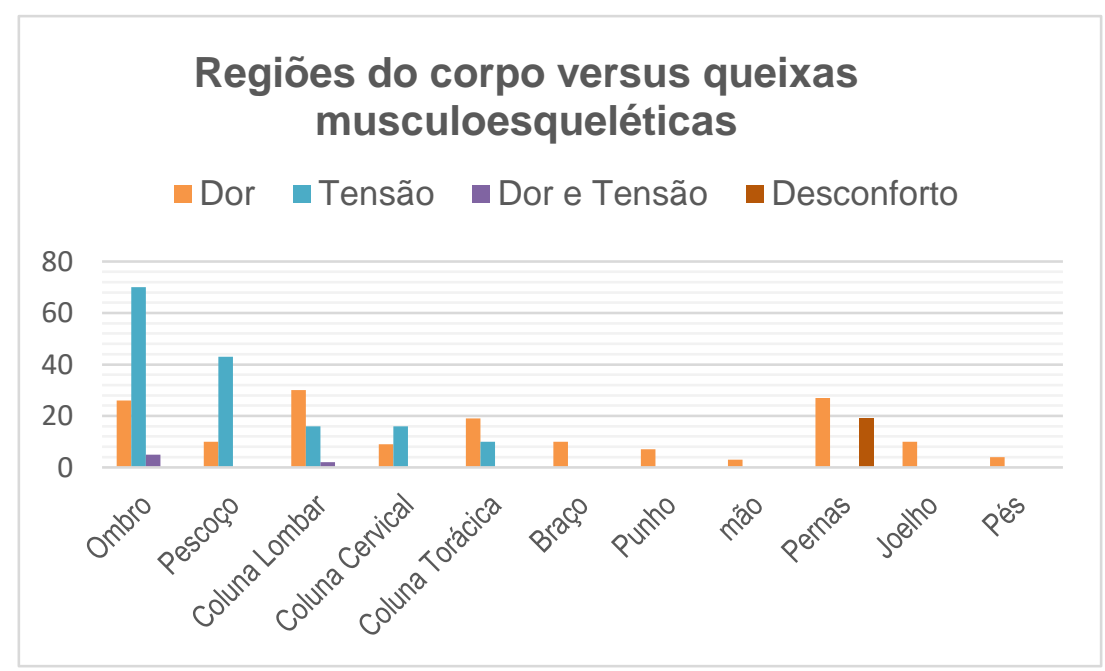

Fonte: Autores (2021).

\section{Discussão}

Este estudo analisou o feedback de participantes do curso ministrado na modalidade híbrida para 257 professores da rede municipal de ensino de São Paulo. Por meio da análise de 1219 apontamentos realizados pelos professores ao longo do curso, foi possível identificar diferentes queixas relacionadas à saúde, ambiente e organização de trabalho. 
Por meio dos relatos dos professores, verificou-se que a maior parte das queixas esteve relacionada ao ambiente e organização de trabalho e foram registradas no módulo "Voz no trabalho docente" (Tabela 1), como o esperado, uma vez que esse módulo expunha as condições adversas do trabalho deste profissional.

Em relação ao ambiente, especificamente, as queixas relatadas foram em relação ao ruído externo e/ou interno a sala, presença de poeira, pó de giz, materiais de limpeza com odor forte, infraestrutura inadequada, presença de ventiladores (por serem barulhentos ao funcionarem ou pelo uso contínuo que leva a irritação na garganta e/ou olhos) e as reformas no período letivo. Quanto aos apontamentos relacionados à organização de trabalho foram mencionados excesso de alunos por sala, indisciplina, falta de materiais, intervalos diferenciados entre turmas, longas jornadas de trabalho, burocracia, inatividade, falta de poder de decisão da Comissão Interna de Prevenção de Acidentes (CIPA), além de queixas de presença de violência e insegurança no ambiente escolar.

Outro estudo realizado no final dos anos 90 também levantou problemas semelhantes, registrando inclusive a ocorrência alta de distúrbio de voz (60\%). Numa amostra representativa de 422 professores, o estudo confirmou o desconhecimento dos participantes sobre o processo de produção vocal, sobrecarga de trabalho, em presença de situações adversas e de ambiente físico inadequado (Ferreira et al., 2003).

Considerando outra realidade, Araújo (2009) realizou um levantamento de estudos epidemiológicos com docentes da Bahia de 1996 a 2007, sendo que 75\% deles apontaram as mesmas queixas de ambiente e organização de trabalho aqui apresentadas. É interessante notar que entre o último estudo do levantamento e o presente estudo há um intervalo de 20 anos, com regiões do território diferentes, mas com os mesmos problemas persistindo no ambiente escolar (Cortez et al, 2006).

Fica evidente a necessidade de conscientização dos professores, quanto aos aspectos relacionados ao seu ambiente e organização de trabalho, bem como a associação desses com a sua saúde, a fim de serem capazes de identificar possíveis problemas, e saberem onde e como procurar soluções, tornando-os, portanto, agentes transformadores do seu meio e bem-estar.

No presente estudo foram registradas 565 queixas corporais e funcionais (Tabela 2) e considerando o ambiente de trabalho destes professores, não é difícil compreender esse panorama. Os distúrbios osteomusculares relacionados ao trabalho (DORT) são de natureza multifatorial, decorrentes de formas combinadas ou não e possui clara associação com fatores de risco organizacionais e psicossociais, como períodos prolongados e altas demandas de trabalho (Ceballos et al., 2015). Segundo Alves et al. (2014), docentes que trabalham de 21 a 40 horas são os que mais relatam queixas osteomusculares. Quanto mais horas de trabalho, maior a demanda, dentro e fora da sala de aula, aumentando as chances do aparecimento de distúrbios relacionados ao trabalho.

A maioria das queixas musculoesqueléticas (99,75\%) foram registradas, como esperado, no módulo "Corpo, postura e voz". Esse módulo enfatizava a importância de bons hábitos posturais e consciência corporal durante a jornada de trabalho para prevenção de lesões musculoesqueléticas, além de exemplos de alongamentos e exercícios para serem realizados antes, durante e após o expediente. Apesar de mostrar atitudes preventivas e de bem-estar, esse módulo trouxe oportunidade para que os professores expusessem suas queixas de saúde.

As queixas musculoesqueléticas mais comuns foram dor e cansaço, principalmente nos ombros, cervical e lombar, além de desconforto em membros inferiores (Gráfico 1). Oliveira \& Lima (2014) também revelaram em seu estudo um maior predomínio (>70\%, para professores da rede pública) de sintomas musculoesqueléticos nas regiões do pescoço/cervical, ombros, lombar e quadris/MMII. O trabalho do docente exige muito do corpo e da postura. Além das questões citadas, o professor também carrega materiais didáticos, passa horas em pé na sala de aula, ou mesmo horas sentado digitando ao planejar aulas e/ou também fica muito tempo com o membro superior suspenso combinado com leve inclinação anterior do pescoço mais rotação de tronco levando a sobrecarga de diversos segmentos corporais, consequentemente acarretando dores e desconfortos, resultados de movimentos repetitivos e mau posicionamento postural. Os movimentos repetitivos ocasionam microtraumas, enfraquecimento 
dos tecidos, alterações degenerativas e dificuldade para recuperação tissular, levando a um quadro de dor, formigamento, cansaço entre outros sintomas (Sanchez et al., 2014).

Algumas ações podem favorecer as condições de trabalho dos profissionais, como: manter postura adequada durante a atividade desempenhada, fazer revezamento de posições; realizar atividades com alinhamento postural, que não gerem sobrecarga e estabelecer e manter intervalos regulares entre as tarefas, proporcionando descanso físico e psicológico. Ações como essas promovem melhora no desempenho profissional ao mesmo tempo que evitam danos à saúde (Silveira et al., 2020).

Em se tratando dos professores, algumas medidas práticas como saber se posicionar adequadamente, realizar pausas regulares evitando movimentos repetitivos, organizar o mobiliário e os materiais de uso frequente, evitando movimentos excessivos que sobrecarreguem as estruturas osteomusculares são atitudes fundamentais para a manutenção da saúde e bem-estar corporal (Alves et al., 2014). Vale ressaltar que informações e ações educativas relacionadas a essas temáticas não são comuns, nem durante a formação do professor, como ação preventiva, tampouco em atividades de reciclagem e formação continuada. Atores, locutores e cantores, por exemplo, recebem formação a respeito de cuidados com o corpo e com a voz, o que deveria ocorrer também na carreira docente (Luchesi et al., 2010 e Penteado \& Santos, 2015).

As dificuldades enfrentadas para buscar tratamento e orientações por parte dos professores podem estar relacionadas à falta de tempo, dificuldade de deslocamento e custos elevados, elementos comuns na sociedade atual. Assim, ferramentas de promoção em saúde à distância podem ser uma alternativa (Arieira et al., 2009).

O termo Telessaúde se refere a um conjunto de atividades que vai além dos cuidados de saúde, incluindo educação de profissionais e pacientes, além do uso no setor administrativo. É um conceito que vem evoluindo ao longo do tempo para que haja melhor compreensão da saúde de populações e indivíduos não apenas sob o ponto de vista médico, mas também em relação a fatores de risco ambientais e de estilo de vida, tornando-se relevante no desenvolvimento de intervenções para a promoção de saúde e prevenção de doenças e disfunções (Souza et al., 2021). A assistência à saúde remota ou telemedicina vem sendo utilizada nos países desenvolvidos em cuidados de pacientes pós cirúrgicos, por exemplo (Egmond et al., 2018). A partir de março de 2020, com a declaração da pandemia por COVID-19 pela organização Mundial de Saúde (OMS), a telemedicina passou a ser muito mais utilizada, visando o atendimento das pessoas necessitadas, e a educação em Saúde também passou a ser uma prática muito difundida. A Educação em Saúde deve ter dois objetivos principais: levar informação e promover mudança de comportamento (Rosenstock et al., 1988). Em relação ao objetivo informativo, o profissional que trabalha com educação em saúde deve identificar lacunas no conhecimento e oferecer informações. Do ponto de vista da mudança de comportamento, é preciso identificar os pontos a serem trabalhados e as possibilidades e crenças envolvidas na mudança, além da viabilidade econômica.

O presente artigo traz as questões levantadas acima, uma vez que por meio de um curso à distância, utilizando a tecnologia, foi possível mostrar aos professores a importância do autocuidado e também fazer com que percebessem situações ou circunstâncias nocivas relacionadas ao trabalho, problematizando a questão da informação. Do ponto de vista da mudança de comportamento, as aulas com orientações de comportamentos e exercícios serviram como ferramenta para uma possível mudança na rotina. É importante, enfatizar que estratégias de promoção de saúde à distância servem como forma de informar, motivar e orientar, mas não substituem a intervenção fisioterapêutica, fonoaudiológica, médica ou de qualquer outro profissional de saúde. Outro aspecto merece destaque: o fato de os professores terem sido expostos ao referido curso não garante a mudança imediata de comportamento, ou seja, o planejamento de ações de acompanhamento é imprescindível para estabelecer uma rotina que contemple recorrentes observações que integrem as condições do ambiente e da saúde dos professores, assim como a prática efetiva de estratégias para reverter as queixas observadas.

A escolha da modalidade híbrida, com predomínio do EAD como método educacional, possibilitou que o participante (professor) fosse o principal responsável pelo seu processo de ensino-aprendizagem objetivando uma formação crítico-reflexiva 
sobre seu estado de saúde e as condições de trabalho em que vive. Sabe-se, contudo que o sucesso do aprendizado à distância, depende do preparo das pessoas para lidarem com essa tecnologia e o acesso a ela (Arieira et al., 2009).

Abordagens à distância, como forma de promoção de saúde podem ser um meio de atender uma população contemporânea que apresenta novas exigências, no entanto, mais estudos com essa ferramenta são necessários, a fim de analisar e acompanhar os efeitos da intervenção a longo prazo, avaliando pontos positivos, negativos e possíveis ajustes.

\section{Considerações Finais}

Os professores apontaram queixas referentes ao ambiente físico, à organização de trabalho e à distúrbios musculoesqueléticos nos fóruns de discussão do curso "Promovendo o Bem-Estar vocal do professor", mostrando um ambiente de trabalho com infraestrutura precária, sendo que o maior número de apontamentos referem-se a distúrbios músculoesqueléticos e estudos anteriores já estabeleceram uma relação entre os dois fatores.

O curso se mostrou uma ferramenta eficaz para concientização dessa classe trabalhadora, podendo ser usada como alternativa para promoção e prevenção de saúde.

\section{Financiamento}

O presente trabalho foi realizado com apoio do Programa Institucional de Iniciação Científica - Comissão de Ensino e Pesquisa (PIBIC - CEPE) da Pontifícia Universidade Católica de São Paulo e Programa Institucional de Bolsas de Iniciação Científica - Conselho Nacional de Desenvolvimento Científico e Tecnológico (PIBIC - CNPq).

\section{Referências}

Alva et al. (2017). Study of Risk Factors for Development of Voice Disorders and its Impact on the Quality of Life of School Teachers in Mangalore, India. Journal of clinical and diagnostic research: JCDR, 11(1), MC01-MC05. https://doi.org/10.7860/JCDR/2017/17313.9234.

Alves et al. (2014). Postura ergonômica 2 do profissional docente: um estudo de caso do centro de atenção integrada à criança e ao adolescente (CAIC) senador carlos jereissati, em russas-ce. Revista tecnologia \& informação. 1(3): 20-32. https://repositorio.unp.br/index.php/tecinfo/article/download/712/540.

Araújo, T. M. (2009). Condições de trabalho docente e saúde na bahia: estudos epidemiológicos. Educação e Sociedade, 30(107): 427-449. http://dx.doi.org/10.1590/S0101-73302009000200007.

Arieira et al. (2009). Avaliação do aprendizado via educação a distância: a visão dos discentes. Ensaio: Aval Pol Públ Educ, 63:313 - 340. http://dx.doi.org/10.1590/S0104-40362009000200007.

Batista et al. (2010). O ambiente que adoece: condições ambientais de trabalho do professor do ensino fundamental. Caderno de Saúde Coletiva, 18 (2): 234 242. https://docplayer.com.br/16365796-O-ambiente-que-adoece-condicoes-ambientais-de-trabalho-do-professor-do-ensino-fundamental.html.

Camilo et al. (2020). Is a School of Postures program able to reduce pain and improve flexibility and quality of life in workers with musculoskeletal dysfunction? Research, Society and Development, 9(7), e114973806. https://doi.org/10.33448/rsd-v9i7.3806

Cantor et al. (2013). Voice disorders in teachers and their associations with work-related factors: a systematic review. J Commun Disord, $46(2)$ : 143 -155. https://doi:10.1016/j.jcomdis.2013.01.001.

Ceballos, A. G.C \& Santos, G.B. (2015). Fatores associados à dor musculoesquelética em professores: Aspectos sociodemográficos, saúde geral e bem-estar no trabalho. Rev. bras. Epidemiol, 18(3): 702-715. http://www.scielo.br/scielo.php?script=sci_arttext\&pid=S1415-790X2015000300702\&lng=en. http://dx.doi.org/10.1590/1980-5497201500030015.

Coelho et al. (2020). A Prevalência da síndrome do ombro doloroso (SOD) e sua influência na qualidade de vida em professores de uma instituição privada de nível superior na cidade de Lauro de Freitas, Bahia. Revista Baiana de Saúde Pública, 34 (1): 19-29. DOI: https://doi.org/10.22278/2318-2660.2010.v34.n1.a89

Cortez et al. (2017). A saúde docente no trabalho: apontamentos a partir da literatura recente. Caderno de saúde coletiva, 25(1): 113-122. http://www.scielo.br/scielo.php?script=sci_arttext\&pid=S1414-462X2017000100113\&lng=en.

Delcor et al. (2004). Condições de trabalho e saúde dos professores da rede particular de ensino de Vitória da Conquista, Bahia, Brasil. Cad. Saúde Pública, 20(1): 187-196. https://doi.org/10.1590/S0102311X2004000100035.

Egmond et al. (2018). Effetivensess of physiotherapy with telerehabilitation insurgical patients: a systematic review and meta-analysis. Physiotherapy, 104(3):277-298. 10.1016/j.physio.2018.04.004. 
Ferreira et al. (2015). Bem-Estar Vocal de Professores: Relato de Experiência do Programa Municipal de São Paulo. In: Ferreira LP, Andada e Silva MA, Giannini SPP, organizadoras. Distúrbio de Voz Relacionado ao Trabalho: práticas fonoaudiológicas, p. 135-141.

Ferreira et al. (2019). Intervenção fonoaudiológica com professores: análise de uma proposta realizada à distância. Distúrbios da Comunicação. (31) 2. https://doi.org/10.23925/2176-2724.2019v31i2p234-245.

Ferreira et al. (2003). Condições de produção vocal de professores da rede do Município de São Paulo. Distúrb Comunic. 2003;14(2):275-308. https://doi.org/10.1590/S1516-18462007000100011.

Giannini et al. (2012) Distúrbio de voz e estresse no trabalho docente: um estudo caso-controle. Caderno de Saúde Pública, (28) 11, 2012. https://doi.org/10.1590/S0102-311X2012001100011.

Houtte et al. (2012). Voice disorders in teachers: Occupational risk factors and psycho-emotional factory. Logopedics Phoniatrics Vocology, 37(3): 107-116. https://doi:10.3109/14015439.2012.660499.

Latino, M. L. (2009). O modelo de ativação do desenvolvimento psicológico e suas implicações no contexto de formação e implementação na educação préescolar. In: Pereira, D. A. Análise da capacidade de trabalho e das condições térmicas e acústicas às quais estão submetidos os professores de escolas públicas municipais de João Pessoa. (Mestrado em Engenharia de Produção). Paraíba: UFPB; 2003.

Luchesi et al. (2020). Ações de promoção e prevenção à saúde vocal de professores: uma questão de saúde coletiva. Revista CEFAC, 12(6): 945-953. http://dx.doi.org/10.1590/S1516-18462010005000112.

Machado et al.(2010). Utilização da telemedicina como estratégia de promoção de saúde em comunidades ribeirinhas da Amazônia: experiência de trabalho interdisciplinar, integrando as diretrizes do SUS. Ciênc. saúde coletiva, 15(1): 247-254. http://www.scielo.br/scielo.php?script=sci_artte xt\&pid=S1413$81232010000100030 \& \operatorname{lng}=$ en.

Mango et al. 2012). Análise dos sintomas osteomusculares de professores do ensino fundamental em Matinhos (PR). Fisioterapia e Movimento, 25(4): 785-794. http://www.scielo.br/scielo.php?script=sci_arttext\&pid=S0103-51502012000400011\&lng=en.

Ministério do trabalho. (2018). LER/Dort afastaram 22 mil trabalhadores das atividades profissionais em 2017. http://www.trabalho.gov.br/noticias/6194-lerdort-afastaram-22-mil-trabalhadores-das-atividades-profissionais-em-2017.

Ministério da Saúde. (2012). Dor relacionada ao trabalho: lesões por esforços repetitivos (LER) distúrbios osteomusculares relacionados ao trabalho (DORT). Secretaria de Vigilância em Saúde. http://bvsms.saude.gov.br/bvs/publicacoes/dor_relacionada_trabalho_ler_dort.pdf

$\mathrm{Ng}$ YM et al. (2019). Psychosocial factors, depression and musculoskeletal disorders among teachers. BMC Public Health, 19(1): 234. https://doi:10.1186/s12889-019-6553-3.

Oliveira, A.H, \& Lima, M. C. (2014). Dor lombar e sintomas musculoesqueléticos em docentes do ensino fundamental I e II. Fisioterapia Brasil, 15(2). http://portalatlanticaeditora.com.br/index.php/fisioterapiabrasil/article/view/324

Oliveira M, P. (2012). Refletindo acerca da voz do professor e da necessidade de um planejamento específico para sua aplicabilidade em sua sala de aula. Revista eletrônica de educação da faculdade Araguaia, 3: 40-53. <https://www.fara.edu.br/sipe/index.php/renefara/article/download/120/106.

Penteado, Z. R., \& Santos, V. B. (2015). Ações educativas em grupos de vivência de voz. Distúrbios da Comunicação, 27(2): xxx-yyy. https://revistas.pucsp.br/dic/article/view/20437/16985.

Regis Filho et al. (2009). Lesões por esforços repetitivos /distúrbios osteomusculares relacionados ao trabalho de cirurgiões dentistas: aspectos biomecânicos. Produção. 19(3):569-580. <http://www.scielo.br/scielo.php?script=sci_arttext\&pid=S0103-65132009000300013\&lng=en\&nrm=iso>. ISSN 1980-5411.

Rosenstock et al. (1988). Social learning theory and the Health Belief Model. Health education quarterly, 15(2), 175-183. https://doi.org/10.1177/109019818801500203

Sanchez et al. (2013). Incidência de dor musculoesquelética em docentes do ensino superior. Revista Brasileira de medicina do trabalho, 11(2): 66-75. http://www.rbmt.org.br/how-to-cite/70/pt-BR.

Silveira, J. da S., Cezar-Vaz, M. R., \& Xavier, D. M. (2020). Análise ergonômica e de alterações osteomusculares em trabalhadores: revisão integrativa. Research, Society and Development, 9(11), e349119500. https://doi.org/10.33448/rsd-v9i11.9500.

Souza et al. (2017). Desafios da prática docente. Revista Educação Pública. <https://educacaopublica.cecierj.edu.br/artigos/17/19/desafios-da-prtica-docente>.

Souza et al. (2021). Modelos conceituais utilizados na avaliação de iniciativas de Telessaúde: Protocolo de uma revisão de escopo. Research, Society and Development, 10(6), e38910615913. https://doi.org/10.33448/rsd-v10i6.15913 